\title{
Reflections on 20 years of RNA science
}

\author{
ANDREW FEIG \\ Department of Chemistry, Wayne State University, Detroit, Michigan 48202, USA
}

I joined the RNA Society in 1995 as I started my post-doctoral fellowship in Olke Uhlenbeck's Laboratory at the University of Colorado, Boulder. With the Cech, Uhlenbeck, and Pardi Labs all studying them, catalytic RNAs were a central topic of conversations - in the lunchrooms, in the hallways, at RNA Club, and of course in the pages of RNA. At the time, Olke and I together with others in the lab were developing methods to find and analyze the metal ion binding sites within the hammerhead and understand whether they were structural or functional in nature. The ribozyme and catalytic RNA sessions at the RNA Society Meeting were among the best-attended and featured heated debates and intense questioning from Dan Herschlag among others about the experimental design and what could really be interpreted from the kinetic analyses. That year Steve Scaringe founded a company called Dharmacon to sell synthetic RNAs. The catalog was thin, but the ability to order up a sequence rather than synthesize it ourselves was awesome. Only a handful of RNA structures had been determined and riboswitches had yet to be discovered. SELEX was being used by a wide variety of laboratories to evolve novel ribozymes, but reports of new naturally occurring ribozymes were few and far between. Everyone wondered why there were so few examples of these extraordinary catalysts.

The pace of change within the RNA community has been staggering in the 20 years since then, and the RNA journal has been there every step of the way. The ability to easily synthesize RNAs initiated a revolution in the area of RNA structure. First came the hammerhead ribozyme, then the P4-P6 structure, and several years later the ribosome. Now hardly a week goes by without the announcement of another RNA whose structure has been solved. These high-resolution structures led to corresponding developments in the area of structure prediction. Today, RNA modeling is still an art. De novo in silico folding is possible but computationally intensive even for modest RNAs. When coupled with constraints from methods like FRET, SHAPE, or CryoEM, RNA modeling can yield highly accurate structures for mid-sized molecules, however, and the methods will only continue to improve. This structural revolution dramatically changed the way

\footnotetext{
Corresponding author: afeig@chem.wayne.edu

Article and publication date are at http://www.rnajournal.org/cgi/doi/ $10.1261 /$ rna.050542.115. Freely available online through the RNA Open Access option.
}

RNA scientists go about their work due to the level of structural detail at which we can think about RNA function.

The second transformational change came with the discovery of non-coding RNAs and the recognition that these molecules serve complex regulatory roles. Many of us remember a plenary session from the 6th RNA Society Meeting (2001) in Banff at which the Tuschl Lab presented the first RNAi knockdown in HeLa cells. Nearly everyone in attendance walked out of this talk astounded at what was clearly an historic revelation. Attendees left the session reaching for their cell phones to call their labs as it clearly demonstrated a technique that one could use immediately with nothing more than the purchase of two short RNAs. Steve Scaringe was about to be a rich man and Dharmacon was there, ready to take on this massive surge in demand. This RNAi story turned out to be just the tip of a huge iceberg, an entry point to a vast area of biology that had been hiding in plain sight. Small regulatory RNAs have now been discovered in virtually every organism from bacteria to humans and the complex network of their interactions is still being unveiled. The basic mechanisms of small regulatory RNAs is now pretty well understood, although important details are still being elucidated. The application to controlling human biology has been difficult, but companies continue to pursue this avenue with zeal. The intricacies of these dynamic networks requires greater knowledge, to understand the interplay of signals across these complex systems, to control them and improve human health.

Small non-coding RNAs were not the only regulators awaiting discovery, however. Soon after the microRNA revolution, long-non-coding RNAs (lncRNAs) became recognized as important players in biology as well. Coupled with the ENCODE project and the recognition that virtually every base of genomic DNA is transcribed at some level, it became apparent that these lncRNAs have discrete functions. The interplay between lncRNAs and epigenetics is now clear which makes them highly complementary to miRNA regulation. Due to their sheer size and complexity, however, lncRNAs have been slow to divulge their secrets and their structures. Given the number of laboratories currently exploring them, the next decade will see much greater clarity of their function.

(C) 2015 Feig This article, published in $R N A$, is available under a Creative Commons License (Attribution-NonCommercial 4.0 International), as described at http://creativecommons.org/licenses/by-nc/4.0/. 
The third major transformation in RNA science over the past 20 years is a result of high throughput technologies. First the microarray and then the rapid increase in accessibility of high throughput sequencing (HTS) dramatically changed the landscape of scientific inquiry. RNA science continues to benefit from these methods through the creativity of our community. Colleagues have devised new ways to map global transcription to understand the complement of RNAs in the cell at any moment and under any condition. The exquisite sensitivity of these methods, and innovative ways to select subsets of those RNAs, recently showed that even transient RNAs contain a wide range of post-transcriptional modifications. Such modifications were once thought to be solely for the long-lived functional RNAs like tRNAs, mRNAs, and snRNPs - molecules worth the investment of metabolic energy. As we continue to catalog these modification sites, we are likely to uncover yet another layer of regulation that we still do not fully appreciate.

As we look forward toward the next 20 years of RNA science, what new revelations and mysteries await us? What are the key scientific questions that remain unsolved? In terms of RNA-based tools, the CRISPR-Cas9 system is clearly on the scene. Easy genome editing will be a transformative technology as important as RNAi. Whether it is next year or five years from now, no one will be surprised when this technology receives Nobel recognition. But what is the discovery that lies farther afield and thus is less obvious? Clues are coming out of the microbiome project that imply our complement of symbiotic organisms communicate with each other and with our bodies much more than we have giv- en them credit for. How is this communication mediated? Circulating RNAs have been discovered and people have hypothesized a host of different functions for them. Are they actively released to communicate between cells at a distance, or as a cell dies, does it divulge some of these RNAs as a signal? Do RNAs from one organism have the ability to regulate processes in another? The primitive bacterial immune system that CRISPR represents makes me wonder what other ways bacteria have developed to interact with and respond to their hosts. Given the vast communities of microbes in our GI tract, there is the possibility for some really spectacular discoveries and I wonder whether RNAs will be central players in some of them.

Many creative and ingenious individuals make up our RNA community. We adapt to new paradigms and invent technologies that take us to new heights. We pay attention to our own field but also to the scientific discoveries from other disciplines and make them our own. We train our students to focus deeply on the problems at hand, while simultaneously keeping an open mind about what we accept as truth. Once upon a time, RNA was viewed as merely an intermediate in the central dogma, a transient molecule from which proteins were synthesized. Today we know that RNA is far more than that. Tomorrow, some of today's closely held truths will likely be proven equally inaccurate. That is the nature of science. But, I have little doubt that we will learn about these new findings by publishing them in the pages of $R N A$ and discussing their implications at the annual meeting of the RNA Society each year. I look forward to the adventure and hope you will join me to share the experience. 

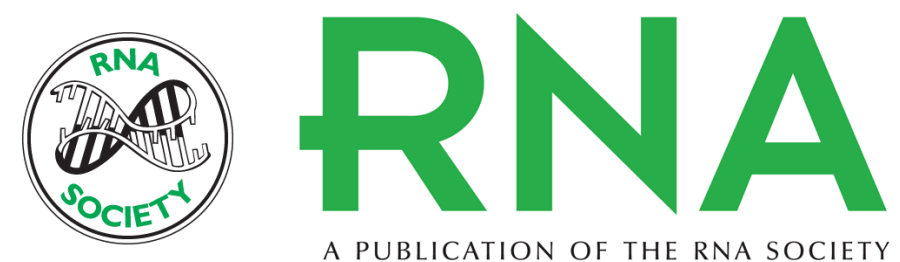

A PUBLICATION OF THE RNA SOCIETY

\title{
Reflections on 20 years of RNA science
}

\author{
Andrew Feig
}

RNA 2015 21: 609-610
Open Access Freely available online through the RNA Open Access option.
Creative This article, published in $R N A$, is available under a Creative Commons License Commons (Attribution-NonCommercial 4.0 International), as described at License http://creativecommons.org/licenses/by-nc/4.0/. Email Alerting $\begin{aligned} & \text { Receive free email alerts when new articles cite this article - sign up in the box at the } \\ & \text { Service }\end{aligned}$ top right corner of the article or click here.

To subscribe to RNA go to:

http://rnajournal.cshlp.org/subscriptions 